\title{
The crystal structure of an $\mathbf{N}$-terminal two-domain fragment of vascular cell adhesion molecule 1 (VCAM-1): A cyclic peptide based on the domain 1 C-D loop can inhibit VCAM-1- $\alpha 4$ integrin interaction
}

\author{
Jia-huai Wang*, R. Blake Pepinsky ${ }^{\dagger}$, Thilo Stehle $\ddagger$, Jin-huan LiU*, Michael Karpusas ${ }^{*}$, Beth Browning ${ }^{\dagger}$, \\ AND LAURELEE OSBORN $\dagger$ \\ *Department of Molecular and Cellular Biology, Harvard University, Cambridge, MA 02138; †Biogen, Inc., 14 Cambridge Center, Cambridge, MA 02142; and \\ ¥Howard Hughes Medical Institute and Department of Molecular and Cellular Biology, Harvard University, Cambridge, MA 02138
}

Communicated by Michael G. Rossmann, Purdue University, West Lafayette, IN, March 6, 1995 (received for review February 13, 1995)

\begin{abstract}
Vascular cell adhesion molecule 1 (VCAM-1) represents a structurally and functionally distinct class of immunoglobulin superfamily molecules that bind leukocyte integrins and are involved in inflammatory and immune functions. X-ray crystallography defines the three-dimensional structure of the $\mathrm{N}$-terminal two-domain fragment that participates in ligand binding. Residues in domain 1 important for ligand binding reside in the $\mathrm{C}-\mathrm{D}$ loop, which projects markedly from one face of the molecule near the contact between domains 1 and 2. A cyclic peptide that mimics this loop inhibits binding of $\alpha 4 \beta 1$ integrin-bearing cells to VCAM-1. These data demonstrate how crystallographic structural information can be used to design a small molecule inhibitor of biological function.
\end{abstract}

A distinct subclass of the immunoglobulin superfamily is represented by the cell surface molecules intercellular cell adhesion molecule (ICAM) 1, 2, and 3 or R, mucosal addressin cell adhesion molecule 1 , and vascular cell adhesion molecule 1 (VCAM-1). These are the only known immunoglobulin-like receptors for leukocyte integrins, a family of heterodimeric proteins essential to leukocyte extravasation and thus to immune surveillance. They have two rather than one pair of cysteine residues in the functionally important $\mathrm{N}$-terminal domain essential for binding to the integrin ligand; the four cysteine residues are conservatively spaced. Because these cell adhesion molecules are essential to leukocyte recruitment and thus to the inflammatory and immune response, they have generated interest as potential targets of antiinflammatory drugs.

VCAM-1 is induced on endothelial cells in culture by inflammatory stimuli such as tumor necrosis factor, interleukin 1, and lipopolysaccharide. It is up-regulated in both early and late atherosclerotic plaques (1-4). It binds to $\alpha 4$ integrins on mononuclear leukocytes, including $\mathrm{B}$ and $\mathrm{T}$ lymphocytes, monocytes, eosinophils, and basophils, but not neutrophils (5). The major form is composed of seven immunoglobulin-like domains, of which domains 1-3 are strikingly homologous in both structure and function to domains $4-6(1,6)$. Rotary shadowing electron microscopy of recombinant soluble sevendomain VCAM-1 indicates an extended, slightly bent rod-like structure for the molecule (10). Structure/function studies indicate that domain 1 (or the homologous domain 4 ) is most important for binding, with the contiguous domain 2 (or domain 5) required at least for stabilization of structure in both recombinant versions and proteolytic cleavage fragments of the molecule (7-9). Although most monoclonal antibodies that block function of VCAM-1 map to domain 1 or its homologue

The publication costs of this article were defrayed in part by page charge payment. This article must therefore be hereby marked "advertisement" in accordance with 18 U.S.C. $\$ 1734$ solely to indicate this fact. domain 4, two distinct functional epitopes map to domain 2 , suggesting that domain 2 may have a role in ligand binding. Mutagenesis studies directed at domain 1 have identified two sets of residues involved in binding, one centered at the required residue Asp-40, and one less important at residues $\mathrm{G}^{64} \mathrm{NEH}(10,11)$.

We report here the crystal structure of a fragment containing the N-terminal two domains of VCAM-1, the only known member of its immunoglobulin superfamily subclass to be so defined. $\S$ The structure consists of two concatenated immunoglobulin modules. The functionally important residue Asp-40 is located at the $i+3$ position of a $\beta$-turn on the corner of the projecting C-D loop of domain 1 . A peptide scan of domains 1 and 2 revealed that only sequences containing this loop were capable of consistently inhibiting VCAM-1- $\alpha 4 \beta 1$ integrin interaction. A cyclic peptide designed to mimic the sequence and structure of this local region showed a marked increase in potency compared to linear peptides and cyclic peptides modified in amino acid sequence.

\section{MATERIALS AND METHODS}

Production of Selenomethionine-Labeled VCAM-D1D2. Seleno-L-methionine (Sigma)-containing VCAM-D1D2immunoglobulin was prepared by the published labeling protocol (12), which we adapted for cells growing on collagencoated beads. VCAM-D1D2-immunoglobulin fusion protein was purified from the supernatant, and functional VCAM-1 fragment comprising the $\mathrm{N}$-terminal two domains (referred to here as VCAM-D1D2) was prepared by limited papain digestion as described (13).

Crystallization and Data Collection. VCAM-D1D2 was crystallized as described (13). The crystals used for structure determination belong to space group C2 with $a=122.09 \AA, b=$ $48.86 \AA, c=73.44 \AA, \beta=117.42^{\circ}$ and contain two molecules per asymmetric unit. The crystals diffract to spacings beyond $2 \AA$. Data were recorded with a Siemens/Nicolet area detector and a rotating anode $\mathrm{x}$-ray generator. A single flash-frozen crystal at $-150^{\circ} \mathrm{C}$ was used for each data set. Data were reduced with BUDDHA (14) and further processed with the CCP4 suite (Science and Engineering Research Council collaborative computer project 4; Daresbury Laboratory, Daresbury, U.K.).

Structure Determination. The structure was determined by multiple isomorphous replacement (MIR) with anomalous

Abbreviations: ICAM, intercellular cell adhesion molecule; VCAM, vascular cell adhesion molecule.

\$The atomic coordinates and structure factors have been deposited in the Protein Data Bank, Chemistry Department, Brookhaven National Laboratory, Upton, NY 11973 (reference 1VSC, R1VSCSF). This information is embargoed for 1 year (coordinates) and 2 years (structure factors) from the date of publication. 
scattering. The first derivative was trimethyl lead acetate at 10 $\mathrm{mM}$. Both isomorphous and anomalous difference Patterson maps calculated at 12-3.5 Å showed one site for each molecule. The second derivative data set (12-2.5 $\AA$ ) was collected from a crystal grown from selenomethionyl variant VCAM-D1D2. Six selenium sites were found in the difference Fourier map, which was phased by single isomorphous replacement plus anomalous scattering of the lead derivative. Heavy atom sites were refined with HEAVY (15) and MLPHARE. The MIR map was of marginal quality. The native Patterson map showed a local dyad parallel to a crystallographic twofold and relating the two independent molecules (13). Twofold averaging of the MIR map permitted a good envelope to be drawn using ENVEDIT (16). The density modification procedure implemented in the program DM, which includes solvent flattening, histogram matching, and twofold averaging, was then applied. The resulting map allowed polypeptide chain tracing for the entire domain 1 and for the framework of domain 2. An initial model was built for one molecule (molecule A) with $O(17)$ and QUANTA (Molecular Simulations). Molecule B was generated with the refined transform from DM. Rigid body refinement, performed at 10-4.5 $\AA$ with X-PLOR (18), revealed that the transformation matrices for the two domains were different. Two separate envelopes for the two domains were generated with MAMA (19) by using the model coordinates with tentative assignment of the missing loops. Three rounds of iterative DM and model building with o revealed $\approx 95 \%$ of the structure, and cycles of refinement with X-PLOR and model building with $O$ eventually allowed completion of the model for both protein molecules and placement of 277 water molecules. The current free (20) and working $R$ factors are $29.4 \%$ and $19.9 \%$, respectively $(F>3 \sigma)$, in the resolution range $15-2.0 \AA$. The model contains all 195 amino acid residues of VCAM-D1D2; the root mean square deviations of bond lengths and bond angles from ideality are $0.016 \AA$ and $2.1^{\circ}$, respectively. A detailed description of the structure determination will be published elsewhere. Table 1 gives statistics on the crystallographic data.

Peptides. A panel of peptides, each 12 amino acids long, was designed to scan all 195 amino acid residues of VCAM-D1D2. The structure of these peptides was biotin-Ser-Gly-Ser-Gly$\mathrm{Xaa}_{12}$, with $\mathrm{Xaa}_{12}$ for peptide 1 representing residues 1-12 of the mature VCAM-1 N-terminal sequence and for peptide 2 representing residues $3-14$, etc. These peptides were synthesized by Chiron Mimotopes using cleavable Multipin peptide synthesis, quantified by automated amino acid analysis at Biogen, and used unpurified. The yield was an average of 1.9 mg of crude (70-80\% pure) peptide per sequence, allowing two assays of each sequence. The remaining peptides were synthesized and purified by Chiron Mimotopes, Research Genetics (Huntsville, AL), or Biogen by standard automated peptide synthesis techniques and HPLC purification. Purity was $>95 \%$ by HPLC and mass spectroscopy. The control peptide dynorphin A was obtained from Sigma.

Cyclization Reactions. Peptides were suspended at 0.1 $\mathrm{mg} / \mathrm{ml}$ in $100 \mathrm{mM}$ ammonium bicarbonate and incubated overnight at $4^{\circ} \mathrm{C}$ with vigorous mixing. The extent of cyclization was determined by HPLC on a $\mathrm{C}_{4}$ column as formation of the ring structure caused the peptide to elute earlier. Cycliza- tion reactions went to $>95 \%$ completion. The peptides were lyophilized and then HPLC purified on a $\mathrm{C}_{4}$ column. The column was developed with a $0-70 \%$ acetonitrile gradient in $0.1 \%$ trifluoroacetic acid. Peak fractions were lyophilized and suspended in water. Peptide concentrations were determined by amino acid analysis.

Assay of Peptides for Inhibition of VCAM-1 Binding. Recombinant soluble VCAM-1 (21) at $1 \mu \mathrm{g} / \mathrm{ml}$ was mixed with $10 \mu \mathrm{g}$ of bovine serum albumin (BSA) per $\mathrm{ml}$ in $50 \mathrm{mM}$ sodium bicarbonate $(\mathrm{pH} 9.2)$ and used to coat Linbro Titertech flat-bottomed 96-well plates at $100 \mu \mathrm{l}$ per well overnight at $4^{\circ} \mathrm{C}$. Coating solution was removed and plates were blocked for $1-2 \mathrm{hr}$ with $100 \mu \mathrm{l}$ of $1 \% \mathrm{BSA}$ per well in PBS at $37^{\circ} \mathrm{C}$ and then washed once with TBS ( $24 \mathrm{mM}$ Tris $\cdot \mathrm{HCl} / 137 \mathrm{mM} \mathrm{NaCl} / 2.7$ $\mathrm{mM} \mathrm{KCl} / 0.1 \% \mathrm{BSA} / 2 \mathrm{mM}$ glucose). Ramos cells (bearing $\alpha 4 \beta 1$ integrin) were cultured and labeled with BCECF-AM as described (7). Peptides dissolved in water or in dimethyl sulfoxide, which previously had been determined not to affect the assay at the concentrations used (a maximum of $10 \%$ ), were diluted in TBS and added to duplicate wells at twice their final desired concentration ( $50 \mu$ l per well). Labeled Ramos cells $\left(2 \times 10^{5}\right.$ cells per well) in $50 \mu$ l of TBS $/ 2 \mathrm{mM} \mathrm{MnCl}_{2}$ were added and allowed to adhere for $30 \mathrm{~min}$ at room temperature, protected from light. Cells were flicked out and wells were washed four times with TBS. Adhesion was determined by measuring fluorescence with a Millipore plate reader. Dynorphin A (Sigma), an unrelated peptide, was used as a negative control, and monoclonal antibody specific for $\alpha 4$ integrin, $\mathrm{HP} 1 / 2$, was used as a positive control for inhibition of VCAM$1-\alpha 4$ integrin binding.

\section{RESULTS}

Structure Description. The structure of VCAM-D1D2 consists of two concatenated immunoglobulin folds as seen in other two-domain fragment structures of cell surface adhesion molecules: CD4-D1D2 (22, 23), CD4-D3D4 (24), and CD2 (25). A schematic representation of the structure is shown in Fig. $1 A$, and an assignment of the $\beta$-strands is given in Fig. 2.

Domain 1 (residues 1-89) belongs to a newly identified I-set of immunoglobulin fold (28). This "intermediate" set resembles a V-set immunoglobulin fold in having conserved conformations for strand $\mathrm{A}$ and for the A-B and E-F loops, but it also resembles the $C 1$-set in lacking the $C^{\prime \prime}$ strand. In addition to the disulfide bond commonly found within the core of immunoglobulin domains (Cys-23-Cys-71 in VCAM-D1D2), another disulfide bond is seen at the edge of the domain between Cys-28 and Cys-75. This additional disulfide bond brings the $\mathrm{B}-\mathrm{C}$ and $\mathrm{F}-\mathrm{G}$ loops in close proximity so that the tip of the domain becomes very compact (Fig. $1 A$ ). The most protruding feature in domain 1 is the C-D loop, near the opposite end of the domain, which carries the functionally important residue Asp-40 $(10,11)$. The structure of this loop, shown in Fig. $1 B$, is stabilized by three internal hydrogen bonds and hydrogen bonds to the E-F loop as well as several solvent molecules surrounding it. Pro-42 appears to be particularly important, since its limited conformational freedom brings the $\mathrm{C}^{\alpha}$ atoms of Thr-37 and Leu-43 within $7 \AA$ of each other. This

Table 1. Crystallographic data

\begin{tabular}{lcccccccc}
\hline Data set & Resolution, $\AA$ & Reflections & Redundancy & Completeness, $\%$ & $R_{\text {merge, }} \%$ & $R_{\text {der }}, \%$ & PP & $R_{\mathrm{c}}, \%$ \\
\hline Native & 2.0 & 23,107 & 4.2 & 87.8 & 5.8 & & & \\
$\mathrm{~Pb}-1$ & 3.5 & 4,941 & 5.8 & 99.0 & 5.6 & 20.1 & 1.1 & 83 \\
$\mathrm{~Pb}-2$ & 3.5 & 4,892 & 14.4 & 98.0 & 8.9 & & & \\
$\mathrm{Se}$ & 2.5 & 13,272 & 5.8 & 92.3 & 6.7 & 8.7 & 1.1 & 73 \\
\hline
\end{tabular}

Data sets $\mathrm{Pb}-1$ and $\mathrm{Pb}-2$ were used for isomorphous and anomalous differences, respectively. $R_{\text {merge }}=\Sigma_{h} \Sigma_{i}\left|I_{h i}-I_{h}\right| / \Sigma_{h i} I_{h i}$. $R_{\mathrm{der}}=\Sigma_{i}\left|F_{\mathrm{PH}}-F_{\mathrm{P}}\right| / \Sigma_{i} F_{\mathrm{P}}$. PP, phasing power (mean value of heavy atom structure amplitudes divided by residual lack-of-closure error). $R_{\mathrm{c}}$, Cullis $R$ factor for centric reflections. Figure of merit is 0.34 for acentric reflections and 0.59 for centric ones. 

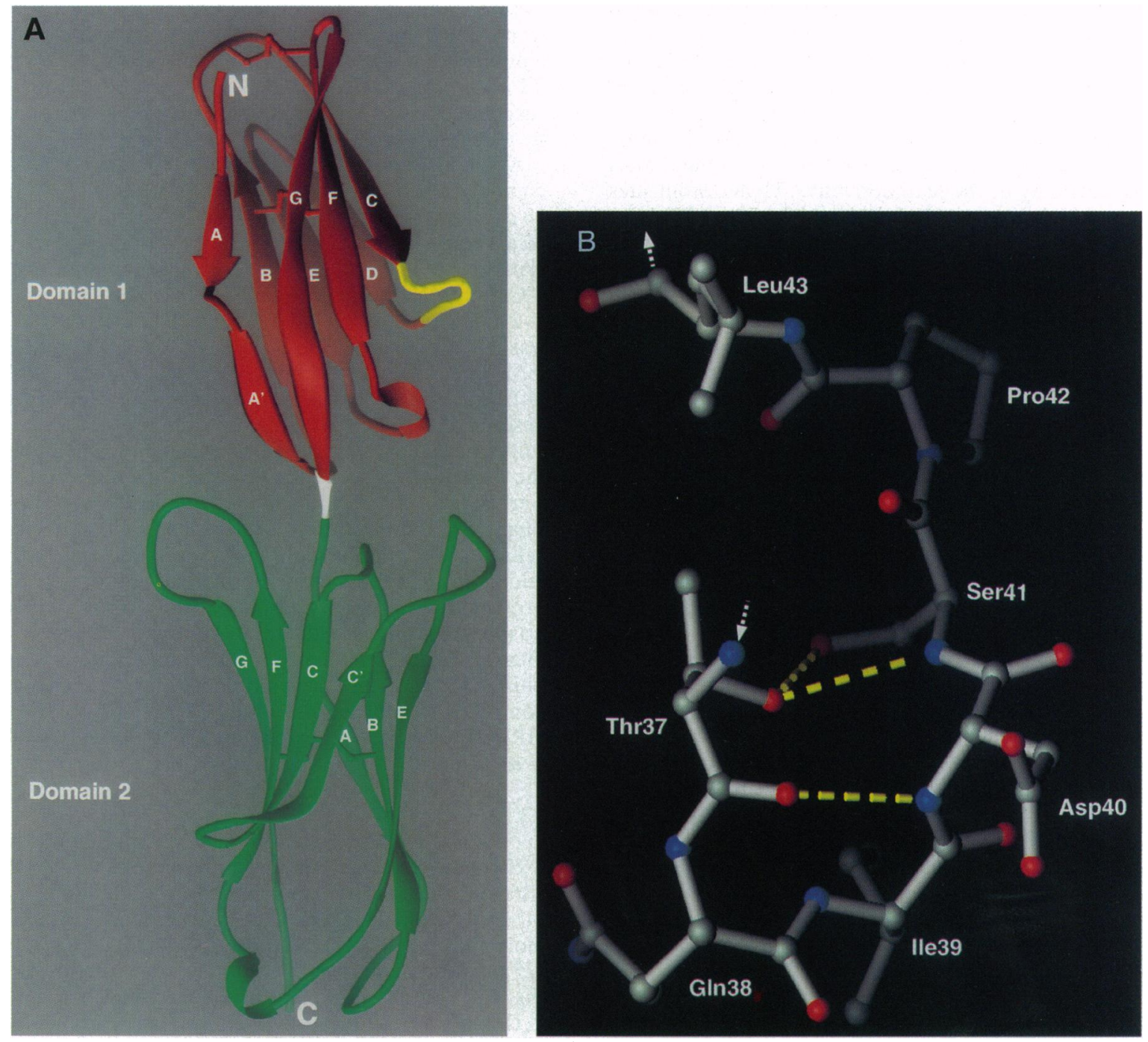

FIG. 1. The structure of VCAM-D1D2. (A) Schematic representation of the molecule. The N-terminal part of the C-D loop (residues 37-43), which contains the critical residue Asp-40, is highlighted in yellow. Tyr-89 is shown in white. (B) Atomic structure of the N-terminal part of the $\mathrm{C}-\mathrm{D}$ loop (residues 37-43). The structure is stabilized by three internal hydrogen bonds (shown in yellow), one of which is found in a $\beta$-turn. Arrows indicate direction of the polypeptide. Both views have been prepared with RIBBONS (26).

loop appears to be an extremely important structural feature of the integrin-binding subclass of the immunoglobulin superfamily.

Domain 2 (residues 90-195) is best described as a C2-set immunoglobulin fold (28). It contains 106 amino acid residues and is therefore considerably larger than the typical C2-set domains, which generally contain $<90$ residues. The difference

$$
\begin{aligned}
& \frac{\text { FKIETTPESRYYLAQIGDSVS்LTCSTTGCESंPFFSWRTQIDSPL NGKVTNE }}{A 1} \frac{\text { CQIDSPC }}{A^{\prime}} \frac{50}{D 1}
\end{aligned}
$$

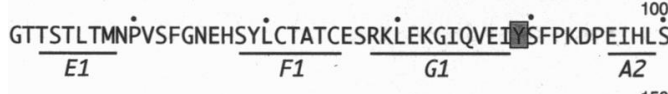

$$
\begin{aligned}
& \text { GPLEAGKPITंVKCSVADVYPंFDRLEIDLLKKGDHLMKSQEF FLEDADRKSLE் }
\end{aligned}
$$

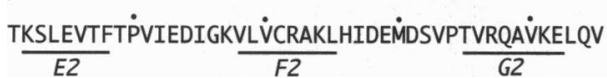

FIG. 2. Secondary structure assignment for VCAM-D1D2. $\beta$-strands are represented by solid lines and were assigned with DSSP (27). Sequence of the N-terminal part of the C-D loop (residues 37-43) is highlighted and paired with the sequence of the most potent cyclic peptide. Residue Tyr- 89 is highlighted as well. in size is reflected in the loop structure-the loops in domain 2 of VCAM-D1D2 are more extensive than those in related structures. They are also rather mobile and characterized by high temperature factors. Moreover, in contrast to domain 1 , the structures of the two copies of domain 2 differ in the loop regions. In general, these differences are small and can be attributed to different packing environments. The open conformation of the F-G loop of domain 2 is unusual; it is, nevertheless, well defined by electron density in both molecules. Parts of this loop (residues 178-180) form an antiparallel $\beta$-sheet with residues $1-3$ of domain 1 of a crystallographically related molecule; this interaction may influence the loop conformation.

The interface between domains 1 and 2 is mainly hydrophobic. The total buried surface area, as calculated with ACCESS, is $800 \AA^{2}$. This area is smaller than that in CD4-D1D2 $\left[1100 \AA^{2}(29)\right]$ but larger than that in CD2 [400 $\left.\AA^{2}(25)\right]$. As shown in Fig. 3, the angle between domains 1 and 2 differs by $12^{\circ}$ in the two molecules. This difference is mainly absorbed by residue Tyr-89, which has the only noticeably different mainchain conformation among the residues that connect the two domains. This appears to justify the designation pivot for Tyr-89.

The relative orientation of the $\beta$-barrels in the two domains is different from CD4-D1D2 or CD2. In VCAM-D1D2, the 

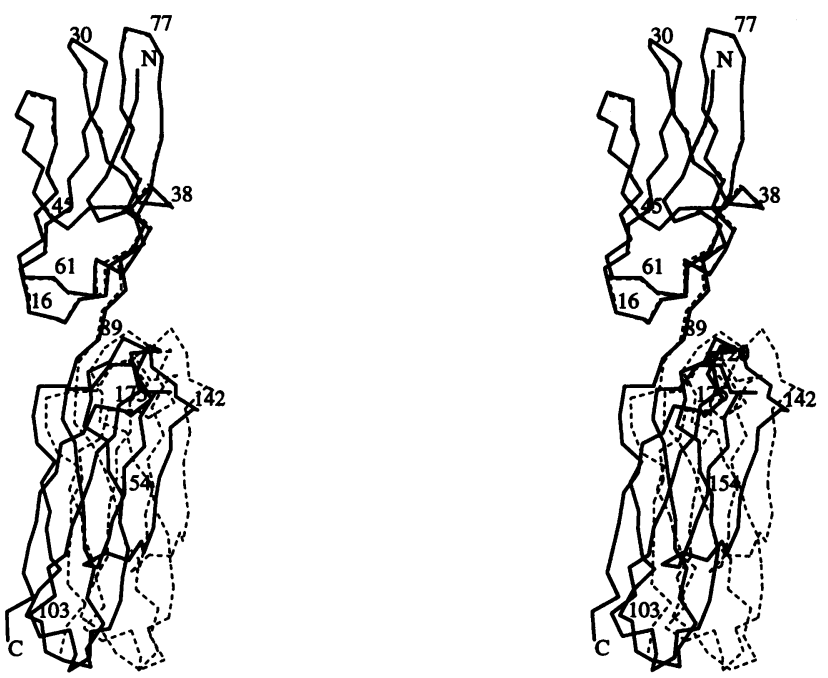

Fig. 3. Stereoview of the two crystallographically independent molecules of VCAM-D1D2. Molecule B has been superimposed onto molecule $A$ using only $C^{\alpha}$ atoms of domain 1 . This view emphasizes the different angles between the domains in the two molecules. Molecules $A$ and $B$ are represented by solid and broken lines, respectively. Some residues are labeled. The figure was prepared by using MOLSCRIPT (30).

angle for rotation of domain 1 onto domain 2 is $130^{\circ}$, whereas in CD4-D1D2 and CD2 this angle is $160^{\circ}$. As a result, the planes of the $\beta$-barrels in VCAM-D1D2 appear to be almost perpendicular to each other instead of roughly parallel.

Peptide Studies. To search for peptides that would interfere with the interaction of VCAM-1 with its counterreceptor $\alpha 4 \beta 1$, we screened a panel of 94 peptides, each 12 amino acids long, designed to scan the entirety of VCAM domains 1 and 2. Each peptide was assayed twice at approximately 1.0 and 0.5 $\mathrm{mM}$ by the assay described in Materials and Methods. Two peptides inhibited well at $1 \mathrm{mM}$ in two separate assays: (biotin-SGSG)-WRTQIDSPLNGK and (biotin-SGSG)TQIDSPLNGKVT, representing amino acids 35-48 of VCAM-1 (Fig. 4A). Interestingly, these peptides include residue Asp-40, which was implicated in binding to leukocyte $\alpha 4 \beta 1$ integrin by site-directed mutagenesis of VCAM-1 (10, 11). Each of these peptides fully includes the protruding C-D loop.

Purified peptides representing this approximate region were also assayed and showed varying degrees of activity as indicated in Fig. $4 A$. The peptide ESPFFSWRTQIDSPLN inhibited as well as the crude peptides, but a pentamer, QIDSP, was inactive. However, a cyclic version of this sequence, CQIDSPC, was the most potent peptide tested. Titration of this peptide shows a clear dose-response relationship (Fig. 4B). A version offset in sequence by 1 amino acid residue, CIDSPLC, was markedly less active, and an unrelated peptide, CPITVKC, was completely inactive, as were various other cyclic peptides tested in parallel (Fig. $4 A$ ). Cyclic peptide CQIDSPC closely mimics loop C-D in the crystal structure of VCAM domain 1.

\section{DISCUSSION}

We have demonstrated that a cyclic peptide can effectively block the adhesion between VCAM-D1D2 and $\alpha 4 \beta 1$ integrin. The sequence of the cyclic peptide CQIDSPC closely mimics that of the C-D loop in domain 1 of VCAM-D1D2. The crystal structure shows that this loop protrudes from the molecule and is easily accessible for contact. The functionally important residue, Asp-40, is located at the corner of the loop. If one were to mutate both Thr-37 and Leu-43 residues into cysteines, a cyclic peptide could be formed easily without disturbing the loop structure significantly. It is therefore likely that the

\begin{tabular}{|c|c|c|}
\hline $\begin{array}{l}\text { Peptide } \\
\text { sequence }\end{array}$ & $\begin{array}{l}\text { Conc. } \\
\text { tested }\end{array}$ & $\begin{array}{c}\% \text { inhibition } \\
\pm \text { SD }\end{array}$ \\
\hline biot-s-WRTQIDSPLNGK & $1.0 \mathrm{mM}$ & $70 \pm 5$ \\
\hline biot-s-TQIDSPLNGKVT & $1.0 \mathrm{mM}$ & $27 \pm 3$ \\
\hline \multirow[t]{2}{*}{ ESPFFSWRTOIDSPLN } & $1.0 \mathrm{mM}$ & $45 \pm 7$ \\
\hline & $.2 \mathrm{mM}$ & $4 \pm 2$ \\
\hline \multirow[t]{2}{*}{ QIDSP } & $1.0 \mathrm{mM}$ & $3 \pm 3$ \\
\hline & $.2 \mathrm{mM}$ & 0 \\
\hline \multirow[t]{2}{*}{ CQIDSPC (cyclic) } & $1.0 \mathrm{mM}$ & $81 \pm 3$ \\
\hline & $.2 \mathrm{mM}$ & $34 \pm 4$ \\
\hline \multirow[t]{2}{*}{ CIDSPLC (cyclic) } & $1.0 \mathrm{mM}$ & $17 \pm 7$ \\
\hline & $.2 \mathrm{mM}$ & 0 \\
\hline \multirow[t]{2}{*}{ CIGDSVC (cyclic) } & $1.0 \mathrm{mM}$ & $8 \pm 4$ \\
\hline & $.2 \mathrm{mM}$ & 0 \\
\hline \multirow[t]{2}{*}{ CPITKVC (cyclic) } & $1.0 \mathrm{mM}$ & 0 \\
\hline & $.2 \mathrm{mM}$ & 0 \\
\hline
\end{tabular}

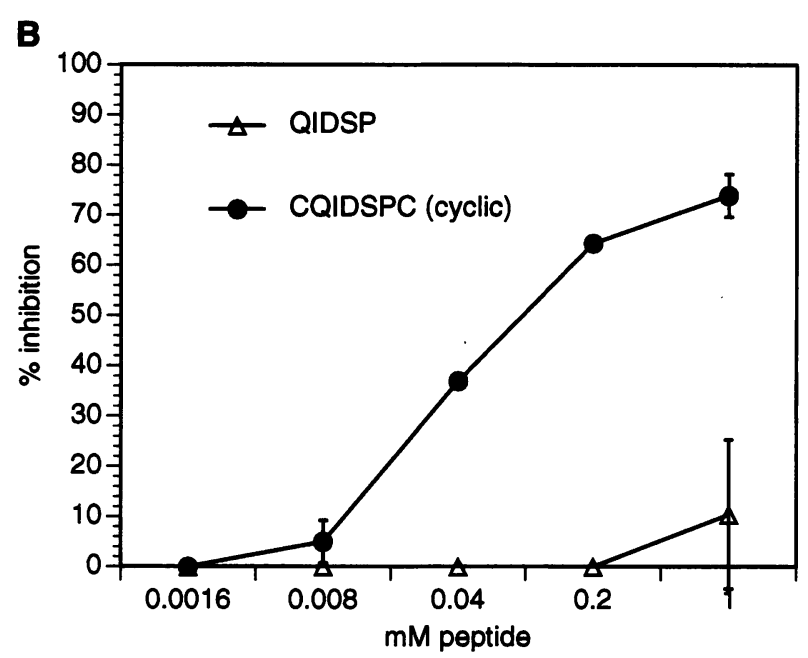

FIG. 4. Effect of synthetic VCAM-1 peptides on adhesion of Ramos cells to purified seven-domain VCAM-1. (A) Peptides were assayed for inhibition of binding as described. Results are expressed as percentage inhibition $\pm \mathrm{SD} ; n=2$ or 3 . (B) Inhibitory cyclic peptide CQIDSPC was titrated and assayed for percentage inhibition of Ramos adhesion in parallel with linear peptide QIDSP. Minor differences in potency in the experiments shown in $A$ and $B$ reflect variability in the biological assay.

synthetic cyclic peptide we have studied adopts a conformation very similar to that part of the C-D loop. The lack of activity of the linear peptide QIDSP indicates that the spatial constraint provided by cyclization is essential for mimicking this part of the C-D loop structure and thus is essential for activity. The failure of cyclic peptide CIDSPLC to inhibit binding, in spite of mutagenic data indicating that residue Gln-38 can be successfully substituted by alanine in the binding site of the intact protein (10), suggests that the positioning of the residues in the loop is important for activity.

The region that includes residues $\mathrm{G}^{64} \mathrm{NEH}$ may also be important for ligand binding (10). This sequence is located in the E-F loop of domain 1, in close proximity to the C-D loop (see Fig. 1A). It might interact directly with the integrin ligand, or it might play an indirect role by stabilizing the structure of 
the C-D loop. There is an extensive network of hydrogen bonds between the C-D and E-F loops, some of which involve the side chain of His-67.

It is known that some members of this subclass of the immunoglobulin superfamily are subverted as viral receptors: murine VCAM-1 for encephalomyocarditis virus (31) and human ICAM-1 for human rhinovirus (HRV) (32). Cryoelectron microscopy of HRV16, "decorated" with a two-domain fragment of ICAM-1, has shown that the tip of domain 1 of ICAM-1 inserts into a canyon on the virus surface (33). The unique "extra" disulfide bond in domain 1 of VCAM-1 makes a narrow and compact tip, which may be necessary for this interaction. Since all members of the VCAM-1/ICAM-1 subclass have this additional disulfide bond, such a compact tip may be a general feature in these structures. In the case of ICAM-1, there is evidence that residues in the B-C and F-G loops that are located immediately beyond the additional disulfide bond play a role in virus binding (ref. 33 and references therein). It is conceivable that the disulfide bond pulls these otherwise quite flexible loops together and orients these important residues for recognition.

The structure of VCAM-1 demonstrates that the binding sites of these cell adhesion molecules for integrins and viruses are located on different regions of the molecule, as indicated by previous data (34). The evidence here, in combination with previous reports that short peptides from fibronectin can also inhibit $\alpha 4 \beta 1$ integrin binding $(35,36)$, could be the basis for an additional integrin binding sequence motif, analogous to the RGD motif found in ligands of several other integrins (37). Our results can, in principle, also serve as a model for blocking interactions in related structures, such as the interaction between CD4 and gp120, by designing peptides that mimic loop structures on the surface of these proteins.

Note Added in Proof. While this manuscript was under review, a manuscript by Jones et al. (38) was published, also presenting crystallographic data on VCAM-D1D2. Their protein was produced in Escherichia coli and crystallized in a different space group. The structure is similar to that presented here.

We thank Stephen C. Harrison for his generous support, advice, and critical reading. We also thank Tomas Kirchhausen for encouragement and members of the Harrison group for helpful discussions. J.-H.W. and J.-H.L. were supported by National Institutes of Health Grant AI 30361 to Stephen C. Harrison.

1. Osborn, L., Hession, C., Tizard, R., Vassallo, C., Luhowskyj, S., Chi-Rosso, G. \& Lobb, R. (1989) Cell 59, 1203-1211.

2. Carlos, T. M., Schwartz, B. R., Kovach, N. L., Yee, E., Rosa, M., Osborn, L., Chi-Rosso, G., Lobb, R. \& Harlan, J. M. (1990) Blood 76, 965-970.

3. Cybulsky, M. I., Fries, J. W., Williams, A. J., Sultan, P., Davis, V. M., Gimbrone, M. A. \& Collins, T. (1991) Am. J. Pathol. 138, 815-820.

4. Alpers, C. E., Hudkins, K. L., Davis, C. L., Marsh, C. L., Riches, W., McCarty, J. M., Benjamin, C. D., Carlos, T. M., Harlan, J. M. \& Lobb, R. (1993) Kidney Int. 44, 805-816.

5. Elices, M. J., Osborn, L., Takada, Y., Crouse, C., Luhowskyj, S., Hemler, M. E. \& Lobb, R. R. (1990) Cell 60, 577-584.

6. Hession, C., Tizard, R., Vassallo, C., Schiffer, S. B., Goff, D., Moy, P., Chi-Rosso, G., Luhowskyj, S., Lobb, R. \& Osborn, L. (1991) J. Biol. Chem. 266, 6682-6685.

7. Osborn, L., Vassallo, C. \& Benjamin, C. D. (1992) J. Exp. Med. 176, 99-107.
8. Pepinsky, B., Hession, C., Chen, L. L., Moy, P., Burkly, L., Jakubowski, A., Chow, E. P., Benjamin, C., Chi-Rosso, G., Luhowskyj, S. \& Lobb, R. (1992) J. Biol. Chem. 267, 1782017826.

9. Vonderheide, R. H. \& Springer, T. A. (1992) J. Exp. Med. 175, 1433-1442.

10. Osborn, L., Vassallo, C., Browning, B. G., Tizard, R., Haskard, D. O., Benjamin, C. D., Dougas, I. \& Kirchhausen, T. (1994) J. Cell Biol. 124, 601-608.

11. Vonderheide, R. H., Tedder, T. F., Springer, T. A. \& Staunton, D. E. (1994) J. Cell Biol. 125, 215-222.

12. Lustbader, J. W., Wu, H., Birken, S., Pollak, S., GawinowiczKolks, M. A., Pound, A. M., Austen, D., Hendrickson, W. A. \& Canfield, R. E. (1995) Endocrinology 136, 640-650.

13. Wang, J.-H., Pepinsky, B., Karpusas, M., Liu, J.-H. \& Osborn, L. (1994) Proteins Struct. Funct. Genet. 20, 287-290.

14. Blum, M., Metcalf, P., Harrison, S. C. \& Wiley, D. C. (1987) J. Appl. Crystallogr. 20, 235-242.

15. Terwilliger, T. C. \& Eisenberg, D. (1983) Acta Crystallogr. A39, 813-817.

16. Blum, M. (1990) Ph.D. thesis (Harvard Univ., Cambridge, MA).

17. Jones, T. A. \& Kjeldgaard, M. (1994) o-The Manual Version 5.10 (Uppsala University, Uppsala).

18. Brünger, A.T. (1992) XPLOR Version 3.1: A System for X-ray Crystallography and NMR (Yale Univ. Press, New Haven, CT).

19. Kleywegt, G. J. \& Jones, T. A. (1994) in From First Map to Final Model, eds. Bailey, S., Hubbard, R. \& Waller, D. (SERC Daresbury Laboratory, Daresbury, U.K.), pp. 59-66.

20. Brünger, A. T. (1992) Nature (London) 355, 472-475.

21. Lobb, R., Chi-Rosso, G., Leone, D., Rosa, M., Newman, B., Luhowskyj, S., Osborn, L., Schiffer, S., Benjamin, C., Dougas, I., Hession, C. \& Chow, P. (1991) Biochem. Biophys. Res. Commun. 178, 1498-1504.

22. Wang, J., Yan, Y., Garrett, T. P., Liu, J., Rodgers, D. W., Garlick, R. L., Tarr, G., Husain, E., Reinherz, E. L. \& Harrison, S. C. (1990) Nature (London) 348, 411-419.

23. Ryu, S.-E., Kwong, P. D., Truneh, A., Porter, T. G., Arthos, J., Rosenberm, M., Dai, X., Xuong, N., Axel, R., Sweet, R. W. \& Hendrickson, W. A. (1990) Nature (London) 348, 419-423.

24. Brady, R. L., Dodson, E. J., Dodson, G. G., Lange, G., Davis, S. J., Williams, A. F. \& Barclay, A. N. (1993) Science 260, 979983.

25. Jones, E. Y., Davis, S. J., Williams, A. F., Harlos, K. \& Stuart, D. I. (1992) Nature (London) 360, 232-239.

26. Carson, M. (1987) J. Mol. Graphics. 5, 103-106.

27. Kabsch, W. \& Sander, C. (1983) Biopolymers 22, 2577-2637.

28. Harpaz, Y. \& Chothia, C. (1994) J. Mol. Biol. 238, 528-539.

29. Garrett, T. P., Wang, J., Yan, Y., Liu, J. \& Harrison, S. C. (1993) J. Mol. Biol. 234, 763-778.

30. Kraulis, P. J. (1991) J. Appl. Crystallogr. 24, 946-950.

31. Huber, S. A. (1994) J. Virol. 68, 3453-3458.

32. Greve, J. M., Davis, G., Meyer, A. M., Forte, C. P., Yost, S. C., Marlor, C. W., Kamarck, M. E. \& McClelland, A. (1989) Cell 56, 839-847.

33. Olson, N. H., Kolatkar, P. R., Oliveira, M. A., Cheng, R. H., Greve, J. M., McClelland, A., Baker, T. S. \& Rossmann, M. G. (1993) Proc. Natl. Acad. Sci. USA 90, 507-511.

34. Staunton, D. E., Dustin, M. L., Erickson, H. P. \& Springer, T. A. (1990) Cell 61, 243-254.

35. Wayner, E. A., Garcia-Pardo, A., Humphries, M. J., McDonald, J. A. \& Carter, W. G. (1989) J. Cell Biol. 109, 1321-1330.

36. Komoriya, A., Green, L. J., Mervic, M., Yamada, S. S., Yamada, K. M. \& Humphries, M. J. (1991) J. Biol. Chem. 266, 1507515079.

37. D'Souza, S. E., Ginsberg, M. H. \& Plow, E. F. (1991) Trends Biochem. Sci. 16, 246-250. 